\title{
A study in the micro-characteristic and electricity properties of silt clay contaminated by heavy metal zinc
}

\author{
Chu Ya ${ }^{\text {i) }}$, Liu Song-yu ${ }^{\text {ii) }}$, Cai Guo-jun ${ }^{\text {iii) }}$ and Bian Han-liang ${ }^{\text {iv) }}$ \\ i) Ph.D Student, Institute of Geotechnical Engineering, Southeast University, Nanjing, Jiangsu, China. \\ ii) Professor, Institute of Geotechnical Engineering, Southeast University, Four arched 2, Nanjing, Jiangsu, China. \\ iii) Associate Professor, Institute of Geotechnical Engineering, Southeast University, Four arched 2, Nanjing, Jiangsu, China. \\ iv) Ph.D Student, Institute of Geotechnical Engineering, Southeast University, Nanjing, Jiangsu, China.
}

\begin{abstract}
More and more attention has been paid to the effects of heavy metal pollution of soil in China, but the studies of physical and electrical properties of the heavy metal contaminated soil is still at the preliminary stage. The related physical properties will change when the soil was contaminated by heavy metal. The electrical property is one of the inherent physical properties of soil; hence the electrical property will change after soil pollution. The muddy silt clay of floodplain in Changjiang River, which is unique in China, was used to study the physical and electrical properties of heavy metal-Zn contaminated soil. In this article, the heavy metal contaminated soil was prepared by adding the solution of zinc nitrate hexahydrate. X-ray diffraction experiment (XRD) and Scanning Electron Microscope test (SEM) were adopted to analyze the mineral and chemical composition of natural silt clay. Besides, particle size analysis, liquid-plastic limit test, $\mathrm{pH}$ test and resistivity test were taken to analyze the variation rules of relevant physical and electrical properties in heavy metal-Zn contaminated soil, in which, the age of fines content test, liquid plastic limit test, mobility test and $\mathrm{pH}$ test was considered to make sure the long-term effects of heavy metal zinc pollution. For electrical properties, the resistivity was used to analyze the soil after contamination. The resistivity that was changed with different pollution concentration, water content was compared. The corresponding relationship of resistivity was established and the evaluation of pollution degree and the polluted area using resistivity was qualitative analyzed in the heavy metal-Zn contaminated silt clay.
\end{abstract}

Keywords: heavy metal-Zn contaminated soil, resistivity, physical and electrical properties, evaluation of pollution degree and polluted area

\section{INTRODUCTION}

With the deepening of urbanization and industrialization process in China, the serious influence of industrialization was engendered in China. So there are many serious problems of environmental pollution, such as atmosphere, rivers and soil, in China.

Main pollution sources of soil pollution are divided into organic and inorganic pollution. Based on "national soil pollution condition investigation gazette" issued by the Ministry of Environmental Protection and the Ministry of Land and Resources, the contaminated soil of China accounts for about $16.1 \%$ of the total land, and the main pollution type is inorganic pollution which accounts for about $82.8 \%$ of the total pollution soil. So the research of heavy-metal pollution is very important. The test and assessment of polluted sites should be carried out before the research and protection working of contaminated soil (Zhu and Liu 2007, Yin et al. 2007, Dermatas and Meng 2003). Based on the results of test got by corresponding test equipment, the research and protection working of contaminated soil will have a good effect.

In this article the heavy metal zinc was chosen as the pollutant, the pollution soils in different conditions and different concentrations were formed indoor to study the engineering characteristic test.

\section{LABORATORY TEST AND METHODS}

Changiiang floodplain phase sediment silt clay with modicum organic matter was used for the test of this paper which is got from a culvert engineering construction site in Hexi, Nanjing. The depth of soil sampling is $5-7 \mathrm{~m}$. The main physical properties of test soil were shown in table 1 .

Table 1 The main physical properties of test soil

\begin{tabular}{ccccc}
\hline Project & $W / \%$ & $r / \mathrm{kN} / \mathrm{m}^{3}$ & $G s$ & $p H$ \\
\hline Result & 36.7 & 19.2 & 2.72 & 7.95 \\
\hline Project & $w_{\text {opt }} / \%$ & $w_{L} / \%$ & $w_{P} / \%$ & $I_{P}$ \\
\hline Result & 18.23 & 37.73 & 23.07 & 10.33 \\
\hline
\end{tabular}




\subsection{Soil sample and preparation}

In order to achieve a good effect of simulating pollution soil and because Zinc nitrate solution is high solubility and cationic high activity, which also has less interference of cement hydration reaction, The reason of choosing, so Zinc nitrate solution was chosen as the source of pollution (Wang et al. 2013, Boardman 1999). The concentrations of zinc pollution $\left(W_{Z n}\right)$ were designed as 50, 500, 5000, 50000mg/kg.

\subsection{Physical property test}

The main tests include particle size analysis test, liquid limit-plastic limit joint test, $\mathrm{pH}$ test and age analysis test. GB/T50123-1999 Standard for soil test method, JTJ051-93 Specifications of highway soil test and ASTM D4972-13 were used to guide the corresponding physical properties test (GB/T50123 1999, ASTM D4972-13 2007). HORIBA pH/COND METER D-54 tester was used for $\mathrm{pH}$ test.

\subsection{Microscopic properties test}

The microscopic properties of contaminated soil were observed and analysed by micro experiment. Through the micro experiment we can know about the change of soil fabric and mineral composition after polluted. The main tests include X-ray diffraction test and Scanning Electron Microscope test.

\subsection{Electrical resistivity test}

The electrical response of heavy metal pollutants is obvious. So the improved round four electrodes Miller Soil Box was used for measuring the resistivity of heavy metal pollution soil, which has stable current and voltage readings. Then the real resistivity will be back calculated by current and voltage readings.

The improved round four electrode Miller Soil Box device used in this article was shown in Fig. 1. The device was fabricated by cylindrical organic glass. The size of improved round four electrode Miller Soil Box is $5 \mathrm{~cm} \times 15 \mathrm{~cm}$ (diameter $\times$ length $/ \mathrm{cm})$. The holes were reserved every $5 \mathrm{~cm}$ on the cylindrical checkerboard for probe injecting measurements.

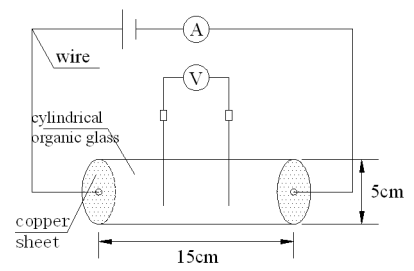

Fig.1 Schematic plot for resistivity test

\section{EXPERIMENTAL RESULTS AND DISCUSSION}

\subsection{Physical property test}

Particle size analysis

By laser particle size analyzer, it is concluded that the change of particle composition of zinc heavy metal pollution soil with different pollution concentration.
From the figure 2, we can see the clay content of natural soil is about $18 \%$, and clay content of pollution soil is increased with the increase of pollution concentration, while silt content is decreased. Grain size curve has an upward trend by the arrows indicated with the increase of concentration. On the other hand, with the increase of ages of soil pollution, the pollution soil with a $0.5 \%$ concentration has decreasing clay content and increasing silt content (as shown in Fig.3).

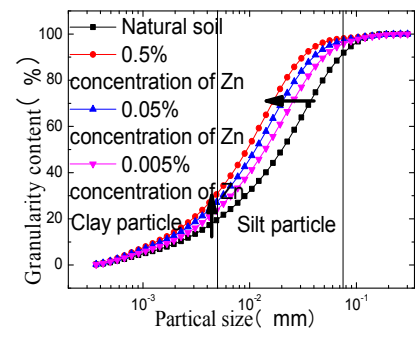

Fig.2 Grading curve with different concentrations

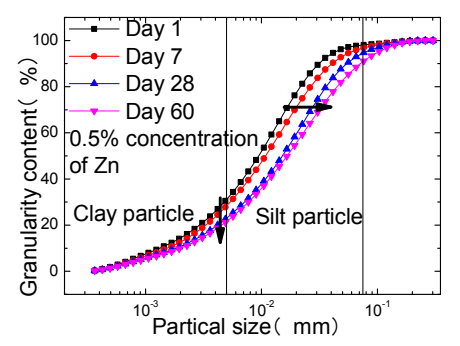

Fig.3 Grading curve with different ages

\section{Liquid-plastic limit test}

The research of liquid plastic limit change of heavy metal pollution soil was used to analyze and evaluate the engineering properties of pollution soil. The relationship about liquid-plastic limit and plasticity index along with the change of pollution concentration were shown in Fig.4 and Fig.5.

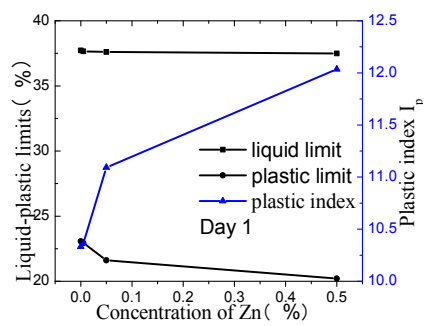

Fig.4 The change of liquid -plastic limit and plastic index with different concentrations

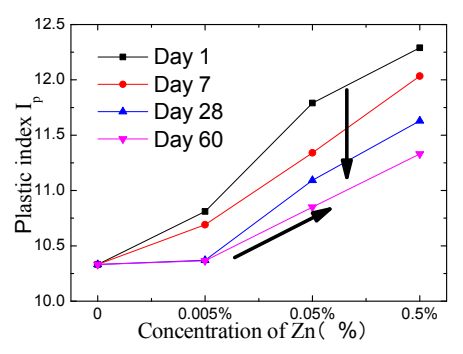

Fig.5 The change of plastic index with different ages
From these figures we can find that, in company with the increase of pollution concentration, liquid limit and plastic limit decrease whereas plasticity index increases; But with the increase of age, the plastic index decreases. The preliminary analysis was got that, in company with the adsorption of heavy metal ion after pollution, the viscosity increases while the combined water decreases so plastic index increased (Cotecchia and Chandler 2000). With the increase of age, acid radical ion of soil release for neutralization, so the plastic index decreases.

\section{pH test}

The acid-base of soil after contamination was analyzed by $\mathrm{pH}$ test. $\mathrm{pH}$ along with the change of concentration and age were shown in Fig.6, from what we can see that the initial $\mathrm{pH}$ value of natural soil is 7.95 , which presents weak alkalinity. With the increase 
of zinc concentration, soil $\mathrm{pH}$ value has a downward trend; with the increase of age the soil $\mathrm{pH}$ value in same pollution concentration pollution also has a downward trend. In this paper, the zinc nitrate soluble salt was used as pollutants which make soil present acidity. So with the increase of zinc pollutant concentration, the $\mathrm{pH}$ of soil is reducing and presenting acidic changes.

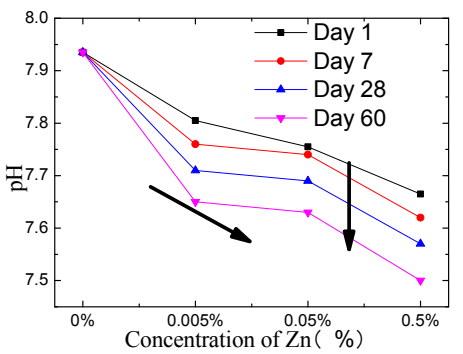

Fig.6 The change of $\mathrm{pH}$ with different ages

\subsection{Microscopic properties test}

In this article we analysis the causes of changes in the engineering properties of heavy metal pollution soil. Changes in the mineral composition and crystal intensity of pollution soil were analyzed by XRD, while the changes of pore, resultant and fabric were analyzed by SEM.

Mineral composition analysis

The reflection intensity curve of silt clay before and after pollution was compared to understand the effects of heavy metal pollution on soil minerals. Then we can analyze the change law in the engineering properties of heavy metal pollution soil. (As shown in figure 7)

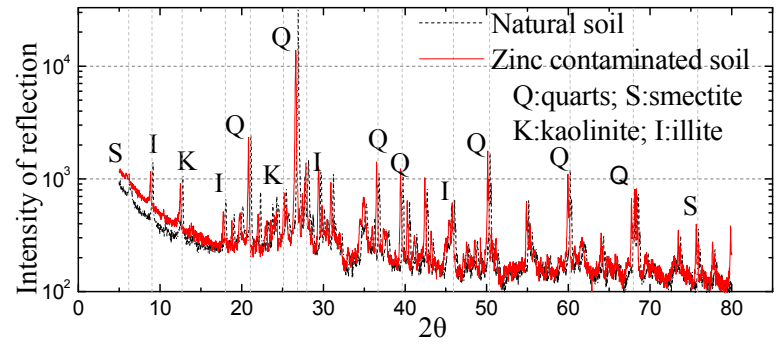

Fig.7 The results of XRD

From the figure 7 , we can see that with the adding of heavy metal zinc, the peak intensity decrease. The decreasing in characteristic peak intensity of quartz was most evident. Among $5^{\circ}$ to $15^{\circ}$, the baseline of pollution soil has an obvious rise, and the wave intensity of kaolinite is significantly reduced. The obvious range of intensity is between $5^{\circ}$ to $30^{\circ}$, The soil viscosity increases and plasticity index rises while the strength of quartz decreases.

Structural and porosity analysis

In this paper, the scanning electron micrograph of the natural and heavy metals zinc pollution soil was compared to analyze the different microstructure of soil after pollution. As shown in figure 8 , there are three kinds of proportion $(5 \mu \mathrm{m}, 10 \mu \mathrm{m}, 20 \mu \mathrm{m})$ for pictures of natural and heavy metals zinc pollution soil. From this figure we can see that the contaminated soil is looser than the natural soil and has more porosity than the natural soil. There are many irregular small particles in natural soil what form the side - side, side - surface transition state (Izdebska-Mucha and Trzciński 2008), on the other hand, the large combos with surface-surface transition state are formed in pollution soil. From the A2 of figure 8 , we can see the fine crystal products $\mathrm{Zn}\left(\mathrm{N}_{3}\right)_{2}$ shown in contaminated soil samples in red circle. The side - side and edge - surface transition state was located in the red oval, as shown in $\mathrm{A} 1, \mathrm{~B} 1$ and $\mathrm{C} 1$ of figure 8 . The pore of soil was illustrated by arrow in A1, A2, B2 and C2 of figure 8, we can see that the contaminated soil is looser than the natural soil and has more porosity than the natural soil.

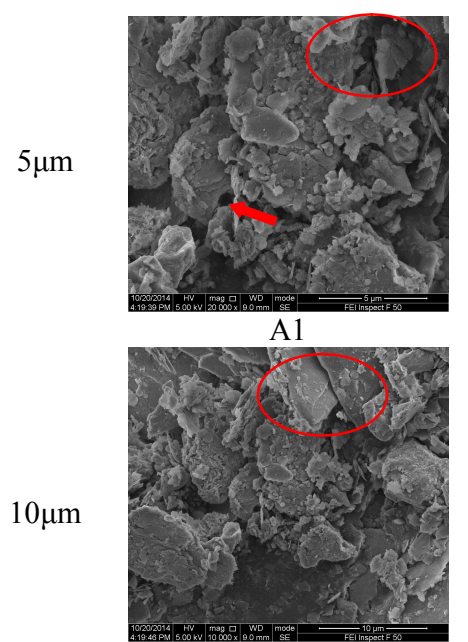

B1

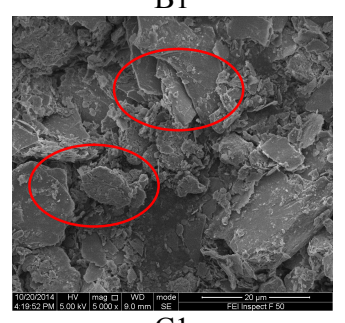

C1

Natural soil

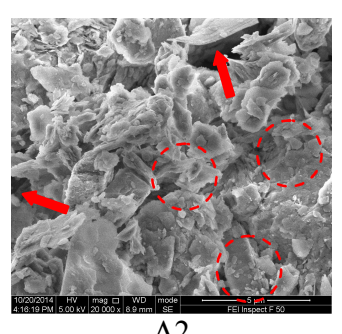

A2

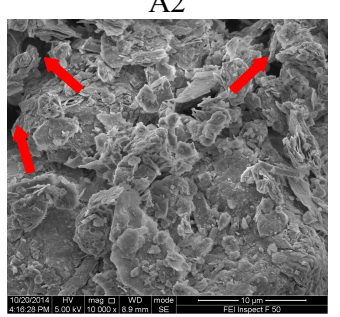

B2

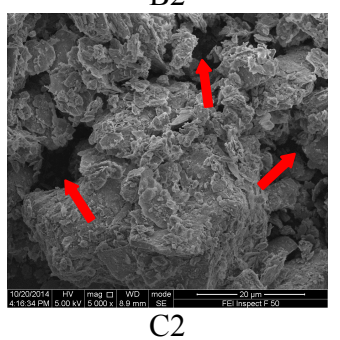

Zn contaminated soil
Fig. 8 The results of SEM

\subsection{Electrical resistivity test}

In this article, the lartificial configured heavy metals zinc pollution sample in indoor are used to quantitative study the change of resistivity. The quantitative relation between the resistivity and pollution concentration is established. The change of heavy metal pollution soil resistivity with age is analyzed.

The relation between resistivity and water content is shown in figure 9, from that we can see the resistivity decreased exponentially with the increase of moisture content and decreased with the increase of pollution concentration. The relation between resistivity and concentration is shown in figure 11 , from that we can 
see the resistivity decreased linearly with the increase of pollution concentration (Lian 2000). The relation between resistivity and age is shown in figure 10 and 12; from that we can see age has a little effect on the resistivity.

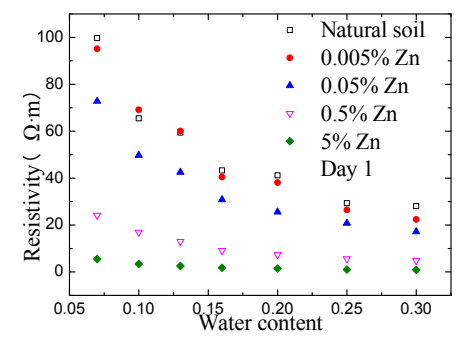

Fig.9 The relationship between resistivity and water content

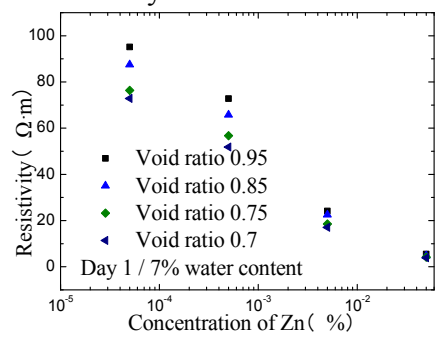

Fig. 11 The relationship between resistivity and concentration

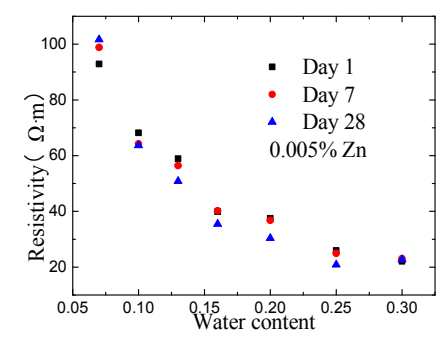

Fig.10 The resistivity measurements with different age

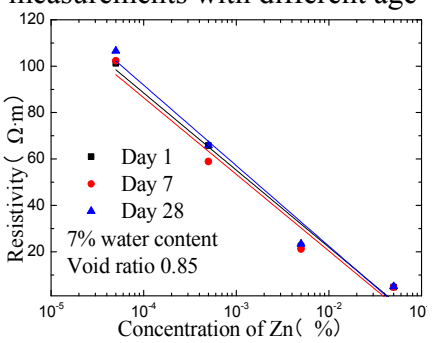

Fig. 12 The resistivity measurement with different age
The relationship between resistivity and concentration is fitting analyzed by figure 11 . The corresponding formula is shown in table 2 :

Table 2 The relationship between resistivity and concentration

\begin{tabular}{ccr}
\multicolumn{4}{c}{ Table 2 The relationship between resistivity and concentration } \\
\hline Void ratio & Resistivity of pollution soil & $\mathrm{R}^{2}$ \\
\hline 0.95 & $\rho=-36.91 \times-31.249\left(\log W_{Z n}\right)$ & 0.974 \\
0.85 & $\rho=-33.85 \times-28.65\left(\log W_{Z n}\right)$ & 0.981 \\
0.8 & $\rho=-31.277 \times-26.4\left(\log W_{Z n}\right)$ & 0.981 \\
0.7 & $\rho=-28.582 \times-23.65\left(\log W_{Z n}\right)$ & 0.988 \\
\hline
\end{tabular}

The relationship between the concentration and resistivity in silt clay codified in:

$$
\rho=a \times b \log W_{Z n}
$$

where $\rho$ is resistivity; $a$ and $b$ are the state parameter of soil; $W_{Z n}$ is concentration of pollution soil.

\section{CONCLUSIONS}

In this article, the related physical, micro and electrical properties of heavy metal pollution soil sample were studied. The relevant tests were compared and analyzed to get the following conclusions:

1. Changes in engineering properties of heavy metal pollution soil were analyzed by the physical experiment. After pollution, the clay content decreases, silt content increases. With the increase of age, plasticity index and $\mathrm{pH}$ decrease and with the increase of concentration, plasticity index increases and $\mathrm{pH}$ decreases.

2. According to microscopic experiment, it is concluded that reflection intensity of quartz decreases with the increase of concentration, the cohesive of soil increases and plasticity index increases. On the other hand, the contaminated soil is looser than the natural soil and has more porosity than the natural soil. There are many irregular small particles in natural soil what form the side - side, side - surface transition state, and the large combos with surface-surface transition state are formed in pollution soil.

3. The corresponding relation between resistivity and concentration was got by the analysis of resistivity. The preliminary evaluation of concentration and scope of pollution soil was got according to the corresponding formula.

\section{ACKNOWLEDGEMENTS}

Majority of the work presented in this paper was funded by the Key Project of Natural Science Foundation of China (Grant No. 41330641), the National Natural Science Foundation of China (Grant No. 41202203), the "Twelfth Five-Year" National Science and Technology Support Plan (Grant No. 2012BAJ01B02), the Foundation for the New Century Excellent Talents of China (NCET-13-0118) and the Foundation for the Author of National Excellent Doctoral Dissertation of PR China (Grant No. 201353). These financial supports are gratefully acknowledged.

\section{REFERENCES}

1) ASTM D4972-13, (2007) Standard Test Method for pH of Soils.

2) Boardman, D. I. (1999). Lime stabilisation: clay-metal-lime interactions (Doctoral dissertation, Loughborough Univers -ity).

3) Cotecchia, F., \& Chandler, R. J. (2000). A general framework for the mechanical behaviour of clays. Géotechnique, 50(4), 431-447.

4) Dermatas, D., \& Meng, X. (2003). Utilization of fly ash for stabilization/solidification of heavy metal contaminated soils. Engineering Geology, 70(3), 377-394.

5) GB/T50123-1999, (1999). The national standard of the People's Republic of China, Standard for soil test method.

6) Izdebska-Mucha D., Trzciński J., 2008. Effects of petroleum pollution on clay soil microstructure. Geologija 50, 68-74.

7) Lian-sheng, T. A. N. G. (2000). Mechanical Effect of Chemical Action of Water on Soil and Analysis on Its Mechanism [J]. Acta Scientiarum Naturalium Universitatis Sunyatseni, 4, 023.

8) Wang, P., Li, J. S., \& Wang, H. F. (2013). Engineering Properties of Heavy Metal Contaminated Soil Affected by EDTA Washing. EJGE, 18, 3909-3917.

9) Yin, C. Y., Ghazaly Shaaban, M., \& Bin Mahmud, H. (2007). Chemical stabilization of scrap metal yard contaminated soil using ordinary Portland cement: strength and leachability aspects. Building and environment, 42(2), 794-802.

10) Zhu, C. P., \& Liu, H. L. (2007). Study on engineering properties of polluted soil. Yantu Lixue(Rock and Soil Mechanics), 28(3), 625-630. 